\title{
Multicomponent training with different frequencies on body composition and physical fitness in obese children
}

\author{
ANA SOFIA R. ALVES ${ }^{1,4}$, TELMA L. VENÂNCIO ${ }^{2}$, SAMUEL ALEXANDRE \\ A. HONÓRIO ${ }^{3,5}$ and JÚLIO MANUEL C. MARTINS ${ }^{2,4}$

\begin{abstract}
${ }^{1}$ Polytechnic Institute of Beja, Department of Arts, Humanities and Sports, Rua Pedro Soares, 7800-295, Beja, Portugal ${ }^{3}$ Polytechnic Institute of Castelo Branco, Rua Prof. Dr. Faria de Vasconcelos, 6000-266, Castelo Branco, Portugal ${ }^{4}$ Research Center in Sports Sciences, Health Sciences \& Human Development, Quinta de Prados, Edifício Ciências de Desporto, 5001-801, Vila Real, Portugal
\end{abstract} \\ ${ }^{2}$ University of Beira Interior/UBI, Department of Sports Sciences, Convento de Santo António, 6201-001, Covilhã, Portugal \\ ${ }^{5}$ Sport, Health \& Exercise Research Unit (SHERU), Rua Prof. Dr. Faria de Vasconcelos, 6000-266, Castelo Branco, Portugal
}

Manuscript received on November 28, 2018; accepted for publication on February 14, 2019

\begin{abstract}
How to cite: ALVES ASR, VENÂNCIO TL, HONÓRIO SAA AND MARTINS JMC. 2019. Multicomponent training with different frequencies on body composition and physical fitness in obese children. An Acad Bras Cienc 91: e20181264. DOI 10.1590/0001-3765201920181264.
\end{abstract}

\begin{abstract}
Introduction: The aim of the study was to compare the effects of ten-week multicomponent training with different exercise frequencies on body composition (BC) and physical fitness (PF) in overweight and obese young children. Methods: 40 children, aged 12-15 (14.77 \pm 1.49$)$, were randomly selected and assigned to experimental groups to train three times/week (EG1) or two times/week (EG2) for 10 weeks and a CG group (no training program). Results: It was shown that experimental groups (EG1 and EG2) improved similarly aerobic capacity (3.8\% and 3.5\%, respectively), muscular strength $(29.7 \%$ and $25.2 \%)$, flexibility $(6.1 \%$ and $9.9 \%)$, body mass index $(5.0 \%$ and $4.6 \%)$, and body fat $(6.4 \%$ and $5.6 \%$ ) from pre- to post-training. $\mathrm{CG}$ group showed no significant improvements on $\mathrm{BC}$ and PF variables. Conclusion: Short-term multicomponent training seems to be effective on PF improvements, independently of the exercise frequency, in overweight and obese young children. However, it seems to be more effective to perform a multicomponent exercise training three times/week to improve muscular strength, body mass index, and decrease body fat percentage. This knowledge should be considered by professionals in physical education or youth sport in order to adapt practical tasks depending on the training purposes.
\end{abstract}

Key words: aerobic, health, obesity, strength, youth, program.

\section{INTRODUCTION}

Obesity is nowadays considered as a main public health problem worldwide and is therefore highly prioritized on the European public health (Bemelmans et al. 2014). The reasons associated

Correspondence to: Ana Sofia Ruivo Alves

E-mail: ana.alves@ipbeja.pt

ORCID: http://orcid.org/0000-0002-0145-2143 to the increase of obesity prevalence are complex and predominately related with low levels of physical activity, unhealthy dietary habits, and sedentary lifestyles (Dooris et al. 2014, Golden and Earp 2012). On the contrary, physical fitness has been considered as a determinant factor of health status (Ortega et al. 2008, Smith et al. 2014), and as a main component for the preservation and enhancement of health and holistic development 
during childhood (Marta 2012). Improving this parameter in children' performance can bring significant benefits such as improvements on cardiorespiratory performance, cardiovascular health, total and abdominal adiposity, anxiety control, self-esteem, academic performance, and decreases on depression levels (Cepero et al. 2011, Kvaavik et al. 2009, Marta et al. 2012). Moreover, it has been reported the longevity of physical fitness levels from childhood to the adulthood (Eisenmann et al. 2005, Stratton et al. 2008).

Actually, children should benefit from the development of strength and cardiovascular parameters, being these two-important healthrelated physical fitness components (Ortega et al. 2008, Taanila et al. 2011). Earlier studies have shown the effectiveness of specific conditioning methods, as endurance training (Wong and Harber 2006), strength training (Hendrickson et al. 2010, Kay and Fiatarone Singh 2006), and more recently concurrent training (Alves et al. 2016a, b, 2017) to improve body composition and physical fitness levels in childhood. In fact, abovementioned studies revolutionized and contradicted the initial ideas concerning to the effects of conditioning methods, as strength training could lead to injuries and influence the natural child growth (Faigenbaum et al. 1996), or even concurrent training may affect the development of muscle strength and/or power in young or elderly (García-Pallarés and Izquierdo 2011, Izquierdo-Gabarren et al. 2010).

Numerous interventions have focused on improving dietary intake and increasing physical activity to reduce obesity in children (Chen et al. 2006, Christodoulos et al. 2006). According to the best of our knowledge, there is no study related to the effects of different exercise frequencies in body composition and physical fitness levels in overweight and obese pubescent children. Therefore, the aim of the present study was to compare the effects of 10-week training periods with different frequencies on body composition (BC) and physical fitness (PF) in overweight and obese young school-aged children. We hypothesized that overweight and obese children would show increases in their physical fitness performances independently from the different exercise frequencies approaches. We also hypothesized that body mass index (BMI) and body fat percentage (BFP) would show improvements at performing multicomponent exercise training three times per week over a consecutive 10 -week period instead of two times per week.

\section{MATERIALS AND METHODS}

\section{SUBJECTS}

The sample consisted of 40 pubescent children (girls and boys) from the school cluster Quinta das Palmeiras (Covilhã, Portugal), that were randomly assigned into different training programs. The body mass and body height were as follows: $69.13 \pm 8.10$ $\mathrm{kg}$, and $1.62 \pm 0.08 \mathrm{~m}$, respectively.

The inclusion criteria were pubescent children aged between 12 and 15 years old (aged $14.77^{\text {th }}$ \pm 1.49 years) with chronic pediatric disease $(>85$ percentile), and without a regular oriented extracurricular (i.e., practice in sports clubs). No subject had regularly participated in any form of training program prior to this experiment for the last 6 months.

All participants and their parents/guardians were informed about study procedures as well as possible benefits and risks. The written informed consent was obtained from parents/ guardians of all participants. The study was approved by the Institutional Review Board of the University of Beira Interior and procedures were in accordance with the latest version of the Declaration of Helsinki.

\section{SAMPLE PROCEDURES}

Forty pubescent children recruited from a Portuguese public high school were randomly assigned to two experimental groups and one 
control group. One experimental group (EG2) performed 10-week period of training twice a week, the other experimental group (EG1) performed 10-week period of training three times per week. The control group (CG) followed the physical education class curriculum and did not have a specific training program. Throughout the pre- and experimental periods, the subjects reported their non-involvement in additional regular exercise programs for developing or maintaining strength and endurance performance besides institutional regular physical education classes.

\section{TRAINING PROCEDURES}

The training program was performed during ten weeks on the same day of the week and on the same morning hour for EG1 (Monday, Wednesday and Friday) and EG2 (Monday, Wednesday) groups. The training program was implemented additionally to physical education classes and composed moderate to vigorous intensities (ACSM 2017) highlighted aerobic, strength and flexibility exercises.

Prior to the training, the subjects warmed up for approximately $5 \mathrm{~min}$ with low to moderate intensity exercises (e.g., running, sprints, joint specific warm-up). At the end of the training sessions, all subjects performed $5 \mathrm{~min}$ of static stretching exercises such as kneeling lunges, ankle over knee, rotation and hamstrings. After the warm-up period, training groups were submitted to aerobic exercises (e.g., team sports, ski, hiking, cycling, aquatic exercises) or combined aerobic and strength training (40 min of aerobic exercises and 10 minutes of strength exercises). The aerobic tasks were developed based on an individual training volume that was set to approximately $75 \%$ of the established maximal oxygen consumption $\left(\mathrm{VO}_{2} \mathrm{max}\right)$ achieved on a previous test. After 4 weeks of training, the experimental groups were reassessed using 20-m shuttle run test to readjust the volume. Each training session lasted approximately 60 minutes.

Before the start of the training, subjects completed two familiarization sessions to practice the routines they would further perform during the training period (e.g., 20-m shuttle run test). During this time, the children were taught about the proper technique on each training exercise, and any of their questions were properly answered to clear out any doubts. During the training program there was a constant concern to ensure the necessary security and maintenance of safe hydration levels, as well as to encourage all children to do their best to achieve the best results. Clear instructions about the importance of adequate nutrition were also delivered. The resources used in physical education classes were a gymnasium, sports hall and snow equipment's. A more detailed analysis of the program can be found in Table I.

The experimental groups were assessed for aerobic capacity (20-m shuttle run test), muscular strength (curl-ups and push-ups tests) and flexibility (back saver sit and reach test) before and after the 10 -weeks of training program. The same researcher performed data collection, anthropometric and physical fitness assessments, and training program.

This study was integrated in Pró-Lúdico: Mais e Melhor Saúde (More and Better Health), is a part of a program to promote healthy living habits, which aims to involve children in fun and dynamic activities, providing interactions on emotional, intellectual, physical, and social parameters to promote a healthy lifestyle starting in childhood to adulthood.

\section{TESTING PROCEDURES}

Anthropometric Measurements. All anthropometric measurements were assessed according to international standards for anthropometric assessment (Marfell-Jones et al. 2006) and were obtained prior to any physical performance test. 


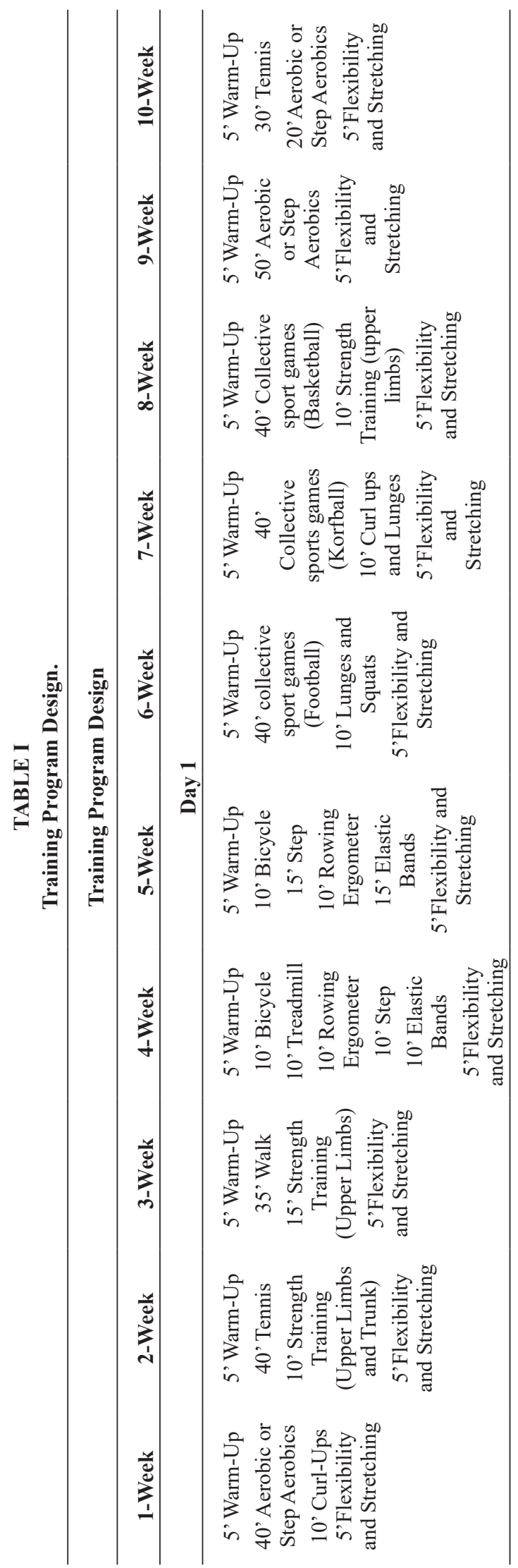

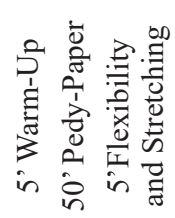

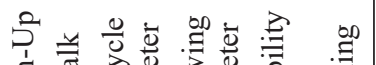

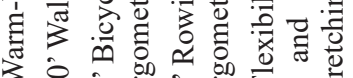

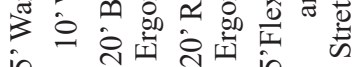

s.

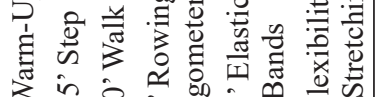

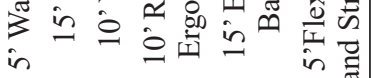

象

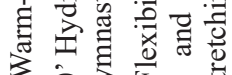

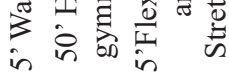

กี้

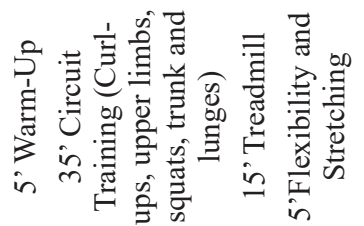

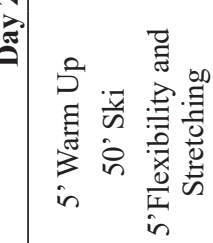

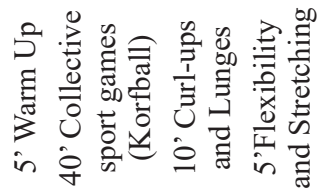

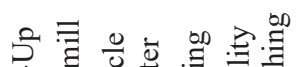

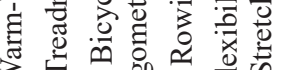

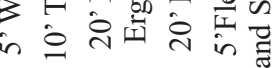

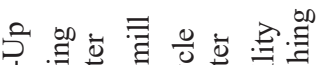

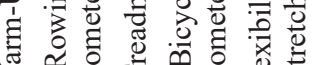

3

20.

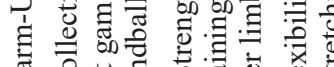

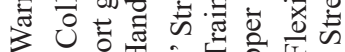

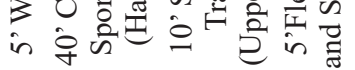

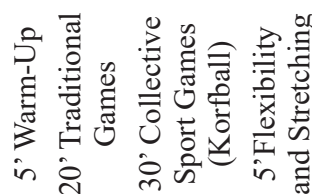

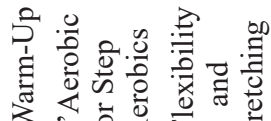

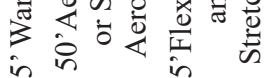

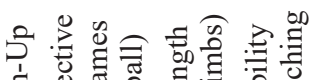

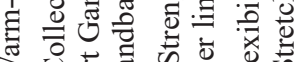

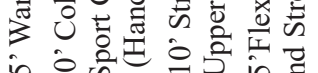

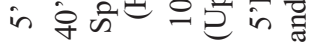

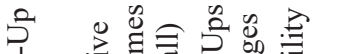

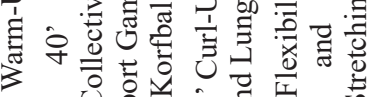

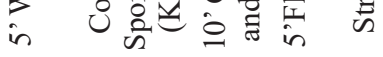

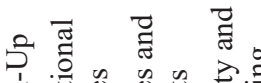

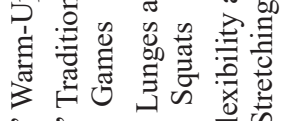
in $\begin{array}{ll}\text { a } \\ \text { in }\end{array}$

?.:

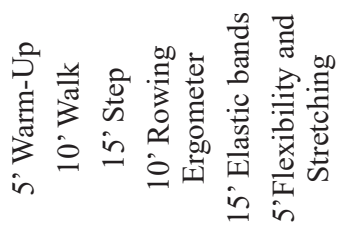

今ิ

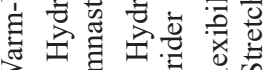
in ô

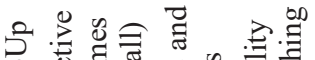

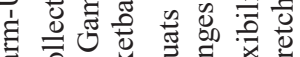

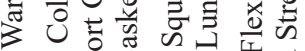

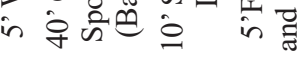

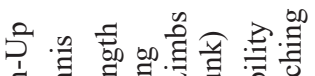

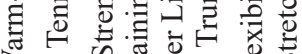

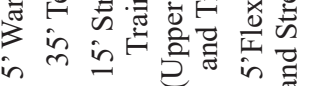

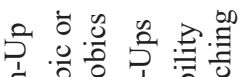
署

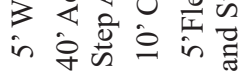


To evaluate body height $(\mathrm{cm})$, a Stadiometer (Seca, model 264, Germany) was used. Body mass $(\mathrm{kg})$ was measured to the nearest $\pm 0,1 \mathrm{~kg}$ using a standard digital floor scale (Soehnle Model L63747, Germany). Subjects were barefoot and wore only underwear. The body mass index (BMI) was calculated by a standard formula = weight $(\mathrm{kg}) /$ [height $(\mathrm{m})^{2}$ ] and associated to a percentile. Thus, children with percentile equal or higher than 85 were classified as pre-obese children and for percentile equal or higher than 95 were characterized as obese children. To determine body fat percentage (BFP) it was used a standard formula: $\mathrm{BFP}=1.2(\mathrm{BMI})$ +0.23 (age) -10.8 (gender) -5.4 (where gender $=$ ' 1 ' for men and ' 0 ' for women). The National Health and Nutrition Examination Survey (Nhanes 2007) were used to assess the health and nutritional status of pubescent children.

To measure physical fitness components (cardiovascular fitness, muscular strength, muscle endurance, and flexibility), four tests of the FITNESSGRAM ${ }^{\circledR}$ battery test were used. The selection of the tests was based on a scientific, as well as the validity and reliability in young population (Ortega et al. 2008, Castro-Piñero et al. 2010). The testing procedures were based by Welk and Meredith (2008).

\section{$20 m$ Shuttle Run Test}

Participants run back and forth between two lines set $20 \mathrm{~m}$ apart. Running pace was gave by audio signals, produced from a CD. The initial speed was $8.5 \mathrm{~km} / \mathrm{h}$, increasing by $0.5 \mathrm{~km} / \mathrm{h}$ every minute. Participants were instructed to run in a straight line, to pivot upon completing a shuttle and to pace themselves in accordance with the time intervals. The test was ended when the adolescent failed to reach the end lines concurrent with the audio signals on two consecutive occasions. Else, the test finishes when the adolescent stops because of fatigue. The final score was calculated as the number of stages completed (precision of 0.5 stages).

\section{Curl-up test}

Participants curl up and slide fingers to other edge of strip in rhythm with CD. Participants were instructed to lie on back with legs bent, arms straight, flat on mat, fingers stretched out and touching the closest edge of measuring strip. Participants curl up and slide fingers to other edge of strip in rhythm with $\mathrm{CD}$, keeping heels on the floor. Back of head should touch the mat on each repetition. Continue assessment until second correction or complete 75 curl-ups.

\section{Push-up test}

Participants had to keep their body straight, performed with a minimum angle of $90^{\circ}$ at the elbow before returning to the arms fully extended position. The number of push-ups to failure was recorded. Males executed the push- ups on the hands and toes while females executed the pushups on the hands and knees.

\section{Back Saver Sit-and-Reach}

The test was administered using an Accuflex I Flexibility Tester as described by Paterson (Patterson et al. 1996). The participant sat at the SR box and fully extended one leg so that the sole of the foot was flat against the end of the box. The participant leaned over the other leg so that the sole of the foot was flat on the floor and $5 \mathrm{~cm}$ to the side of the straight knee. The participant extended the arms forward, putting one hand on top of the other. With palms down, the participant reached forward over the measuring scale as far as possible without bending the knee of the extended leg. Four trials were taken for each leg sides. The four trials averages on each side were used for analyses. 


\section{STATISTICAL ANALYSIS}

Statistical analyses were performed using Statistical Package for Social Sciences (SPSS) v24.0 ${ }^{\circledR}$ for Windows and statistical significance was set at $\mathrm{p} \leq 0.05$. Standard statistical methods were used to calculate the means and standard deviations to describe the data. A two-way mixed ANOVA was performed to analyze if there is influence of different groups after 10 weeks of training on variables physical fitness and body composition variables. The independent variables in the experimental design were groups and evaluation moments. From the two-way mixed ANOVA, it was also possible to analyze the effect size (Partial Eta squared) of the independent variables on the anthropometric and physical performance variables. To interpreting effect size, the cut-offs were based in the Cohen's study (1988).

\section{RESULTS}

It was observed no interaction effect between factors (group and momentum) with any significant differences in all tested variables (Table II). However, when analyzed the effect of factors separately, it was reported significant differences. Regarding to the momentum factor (pre-post training), only curl-up and BMI variables showed a small effect size with significant differences ( $F$ $(2,37)=4.73, \mathrm{p}=0.036 ; \mathrm{\eta} 2=0.113 ; \mathrm{F}(1,37)=8.145$, $\mathrm{p}=0.007 ; \eta 2=0.180$, respectively). Through the post hoc tests, it was observed an improvement on both variables (Curl-up and BMI) after a 10-week training. Although the remaining variables did not present significant differences, it was identified that both experimental groups improved similarly after 10-weeks training (Table III). CG group presented no significant improvements on body composition, neither on physical fitness variables (Table III). Concerning to the group factor, it was only found significant differences on the curl-up variable with medium effect size $(\mathrm{F}(2,37)=6.516$,
TABLE II

Two-way mixed ANOVA analysis.

\begin{tabular}{cccc}
\hline & $\mathbf{G}$ & Pre-Post & $\begin{array}{c}\mathbf{G} \text { * Pre- } \\
\text { Post }\end{array}$ \\
\hline \multirow{2}{*}{ VO $_{2}$ max } & $\mathrm{p}=0.398$ & $\mathrm{p}=0.051$ & $\mathrm{p}=0.284$ \\
& $\mathrm{Eta}=0.049$ & $\mathrm{Eta}=0.099$ & $\mathrm{Eta}=0.066$ \\
Sit and Reach Left & $\mathrm{p}=0.338$ & $\mathrm{p}=0.412$ & $\mathrm{p}=0.641$ \\
& $\mathrm{Eta}=0.057$ & $\mathrm{Eta}=0.018$ & $\mathrm{Eta}=0.024$ \\
Sit and Reach & $\mathrm{p}=0.229$ & $\mathrm{p}=0.357$ & $\mathrm{p}=0.589$ \\
Right & $\mathrm{Eta}=0.077$ & $\mathrm{Eta}=0.023$ & $\mathrm{Eta}=0.028$ \\
& $\mathrm{p}=0.004$ & $\mathrm{p}=0.036$ & $\mathrm{p}=0.256$ \\
Curl - ups & $\mathrm{Eta}=0.260$ & $\mathrm{Eta}=0.113$ & $\mathrm{Eta}=0.071$ \\
Push - ups & $\mathrm{p}=0.719$ & $\mathrm{p}=0.169$ & $\mathrm{p}=0.668$ \\
& $\mathrm{Eta}=0.018$ & $\mathrm{Eta}=0.050$ & $\mathrm{Eta}=0.022$ \\
BMI & $\mathrm{p}=0.586$ & $\mathrm{p}=0.007$ & $\mathrm{p}=0.081$ \\
& $\mathrm{Eta}=0.029$ & $\mathrm{Eta}=0.180$ & $\mathrm{Eta}=0.127$ \\
BF & $\mathrm{p}=0.567$ & $\mathrm{p}=0.281$ & $\mathrm{p}=0.675$ \\
& $\mathrm{Eta}=0.030$ & $\mathrm{Eta}=0.031$ & $\mathrm{Eta}=0.021$ \\
\hline
\end{tabular}

$\mathrm{VO}_{2}$ max: maximal oxygen consumption; Sit and Reach Left: back saver sit-and-reach left; Sit and Reach Right: back saver sit-and-reach right; BMI: body mass index; BF: body fat percentage; G: group factor; Pre-Post: momentum factor; $G^{*}$ Factor: interaction between factors.

$\left.p=0.004 ; \eta^{2}=0.260\right)$, where the EG1 showed better results compared to the EG2 and CG groups (Table II). These results corroborate the hypothesis that overweight and obese children can increase their physical fitness performances independently from the different exercise frequencies approaches, and the hypothesis that would be obtained better results on body composition and body fat percentage performing multicomponent training 3 times/week over a consecutive 10 -week period.

\section{DISCUSSION}

Literature agrees that low- to moderate-intensity resistance should be conducted 2-3 times/week on non-consecutive days (Behm et al. 2017, Hass et al. 2001) but several studies had been focused in one frequency, did not compared different frequencies (Alves et al. 2017, Greening et al. 2011). To the best of our knowledge, there is a lack of evidences about the effects of different training program frequencies 
TABLE III

Descriptive Statistics from Two-way mixed ANOVA.

\begin{tabular}{|c|c|c|c|}
\hline & & Pre-training & Post-training \\
\hline \multirow{3}{*}{$\mathrm{VO}_{2} \max$} & EG1 & $39.19 \pm 3.55$ & $40.66 \pm 4.03$ \\
\hline & EG2 & $38.36 \pm 2.13$ & $39.70 \pm 3.08$ \\
\hline & $\mathrm{CG}$ & $37.89 \pm 4.76$ & $37.94 \pm 4.97$ \\
\hline \multirow{3}{*}{ Sit and Reach Left } & EG1 & $24.60 \pm 5.73$ & $26.10 \pm 4.82$ \\
\hline & EG2 & $22.10 \pm 7.14$ & $24.30 \pm 6.00$ \\
\hline & CG & $21.50 \pm 9.89$ & $21.05 \pm 9.57$ \\
\hline \multirow{3}{*}{ Sit and Reach Right } & EG1 & $25.50 \pm 4.91$ & $26.60 \pm 4.55$ \\
\hline & EG2 & $21.30 \pm 6.18$ & $23.70 \pm 5.69$ \\
\hline & $\mathrm{CG}$ & $21.50 \pm 9.51$ & $21.20 \pm 9.45$ \\
\hline \multirow{3}{*}{ Curl - ups } & EG1 & $44.40 \pm 17.51$ & $57.60 \pm 18.84$ \\
\hline & EG2 & $26.20 \pm 13.05$ & $32.80 \pm 12.54$ \\
\hline & $\mathrm{CG}$ & $28.60 \pm 18.63$ & $28.90 \pm 17.81$ \\
\hline \multirow{3}{*}{ Push - ups } & EG1 & $8.40 \pm 5.93$ & $11.00 \pm 5.33$ \\
\hline & EG2 & $8.70 \pm 4.64$ & $10.50 \pm 3.66$ \\
\hline & $\mathrm{CG}$ & $11.15 \pm 9.65$ & $11.50 \pm 8.31$ \\
\hline \multirow{3}{*}{ BMI } & EG1 & $26.84 \pm 3.56$ & $25.49 \pm 3.26$ \\
\hline & EG2 & $26.07 \pm 1.74$ & $24.87 \pm 2.03$ \\
\hline & $\mathrm{CG}$ & $26.06 \pm 1.45$ & $26.01 \pm 1.45$ \\
\hline \multirow{3}{*}{$\mathrm{BF}$} & EG1 & $28.04 \pm 5.35$ & $26.24 \pm 4.97$ \\
\hline & EG2 & $25.96 \pm 6.29$ & $24.51 \pm 6.08$ \\
\hline & $\mathrm{CG}$ & $26.09 \pm 5.06$ & $26.02 \pm 5.06$ \\
\hline
\end{tabular}

$\mathrm{VO}_{2}$ max: maximal oxygen consumption; Sit and Reach Left: back saver sit-and-reach left; Sit and Reach Right: back saver sit-andreach right; BMI: body mass index; BF: body fat percentage; EG1: group that performed 10-week training three times/week; EG2: group that performed 10-week training two times/week; CG: no training program.

on overweight and obese children. Therefore, the aim of the current study was to compare the effects of 10-week multicomponent training with different frequencies on body composition (BC) and physical fitness (PF) in overweight and obese young school-aged children. The main results confirmed that a multicomponent training program provide similarly improvements on $\mathrm{BC}$ and $\mathrm{PF}$ variables in group which performed three and also two times/ week. However, significant differences were only observed in muscular strength and body composition variables. Through the analysis between groups, it was reported better results on group which performed three times per week. Moreover, no differences were found in post-training in the CG group in any variable related to body composition or physical fitness. The current data may have a significant importance to optimize training methods in overweight and obese children. Our results are consistent with results of previous studies (Greening et al. 2011, Vanhelst et al. 2011), that showed better results on physical fitness values and decreases on body composition values in experimental group constituted by obese students (9months physical activity program, 2 sessions/week), or even was observed significant differences on body mass index (BMI), with decreases in experimental group and increases in control group, after a 12 months long physical activity program. The results of the current study are also congruent with results of a 
previous study (Alves et al. 2017) in this area which were showed significantly decreases on body fat percentage in experimental group constituted by prepubescent girls (8-week concurrent training, 2 sessions/week). Dorgo et al. (2009) verified the effectiveness of different physical training programs on physical fitness levels, however did not observed differences on body composition values. It was observed improvement of flexibility in both training groups but, even though it was not significant differences, the higher results were observed in experimental group which performed two times per week compared to three times per week (sit and reach left: $9.95 \%$ and $6.09 \%$, respectively; sit and reach right: 11.27 and $4.31 \%$, respectively). These results are consensual with Tokmakidis' study (2006) which suggests that high flexibility values are positively associated to obese children. According to our results, a short-term multicomponent training is important to improve physical fitness levels and body composition parameters in overweight and obese young school-aged children. Moreover, performing three times per week is more effective and useful do improve muscular strength and body composition when properly prescribed and supervised. Thus, this evidence highlights the importance of training design in optimizing schoolbased fat loss exercise programmes in childhood. There are some main limitations of present study: (i) the small size of the sample; (ii) there as discrepancy in the range of ages; (iii) nutrition parameters were not evaluated, which should be considered in future studies; (iv) the training-period of 10 weeks was quite short. This study supports the future research in this area, providing positive results on body composition and physical fitness components in overweight and obese children through the application of multicomponent training with different exercise frequencies. Thereupon, this innovative and safe methodology provides a new path to reduce the monotony of training or classes and to prepare the individual for a healthy future.
This knowledge could provide useful tools for professionals to develop efficient training programs but should be also considered in physical education or youth sport in order to adapt practical tasks depending on the training purposes. Nevertheless, we should be cautious, being aware that further research is needed in this matter.

\section{ACKNOWLEDGMENTS}

The authors would like to acknowledge the support of the Quinta das Palmeiras School on this project (More and Better Health). The authors would also thank all students that participated on this project. This work was supported by national funding through the Portuguese Foundation for Science and Technology, I.P., under project UID/ DTP/04045/2019

\section{AUTHOR CONTRIBUTIONS}

Ana R. Alves was involved in the conceptualization of the study, data assessment, data analysis, and the writing of the manuscript. Samuel A. A. Honório and Júlio M.C. Martins were involved in the writing of the manuscript. Telma L. Venâncio was involved in the data assessment and the writing of the manuscript. All authors contributed approved the final version of the manuscript.

\section{REFERENCES}

ALVES AR, MARTA CC, NEIVA HP, IZQUIERDO M AND MARQUES MC. 2016a. Concurrent training in prepubescent children: The effects of 8 weeks of strength and aerobic training on explosive strength and $\mathrm{VO}_{2} \max$. J Strength Cond Res 30(7): 2019-2032.

ALVES AR, MARTA CC, NEIVA HP, IZQUIERDO M AND MARQUES MC. 2016b. Does intra- session concurrent strength and aerobic training order influence traininginduced explosive strength and $\mathrm{VO}_{2}$ max in prepubescent children? J Strength Cond Res 30(12): 3267-3277.

ALVES AR, MARTA CC, NEIVA HP, IZQUIERDO M AND MARQUES MC. 2017. Effects of order and sequence of resistance and endurance training on body fat in elementary school-aged girls. Biol Sport 34(4): 379-384. 
ACSM - AMERICAN COLLEGE OF SPORTS MEDICINE. 2017. Youth Strength Training. Available from: http:// www.acsm.org/public-information/sportsmedicinebasics/ youth-strength-training.

BEHM DG ET AL. 2017. Effectiveness of traditional strength vs. Power training on muscle strength, power and speed with young: a systematic review and meta-analysis. Front Physiol 8: 423.

BEMELMANS WJ, WIJNHOVEN TM, VERSCHUUREN M AND BREDA J. 2014. Overview of 71 European community-based initiatives against childhood obesity starting between 2005 and 2011: general characteristics and reported effects. BMC Public Health 14: 758.

CASTRO-PIÑERO J, ARTERO EG, ESPAÑA-ROMERO V, ORTEGA FB, SJOSTROM M, SUNI J AND RUIZ JR. 2010 Criterion-related validity of field-based fitness tests in youth: A systematic review. Br J Sports Med 44(13): 934-943.

CEPERO MR, LÓPEZ R, SUÁREZ-LLORCA C, ANDREUCABRERA E AND ROJAS FJ. 2011. Fitness test profiles in children aged 8-12 years old in Granada (Spain). J Hum Sport Exerc 6(1): 135-145.

CHEN AK, ROBERTS CK AND BARNARD RJ. 2006 Effect of a short-term diet and exercise intervention on metabolic syndrome in overweight children. Metab Clin Exp 55(7): 871-878.

CHRISTODOULOS AD, FLOURIS AD AND TOKMAKIDIS SP. 2006. Obesity and physical fitness of pre-adolescent children during the academic year and the summer period: effects of organized physical activity. J Child Health Care 10(3): 199-212.

COHEN J. 1988. Statistical power analysis for the behavioral sciences, $2^{\text {nd }}$ ed., Hillsdale, NJ: Lawrence Erlbaum, p. 274380 .

DOORIS M, WILLS J AND NEWTON J. 2014. Theorizing healthy settings: a critical discussion with reference to healthy universities. Scand J of Public Health 42(15): 7-16.

DORGO S, KING GA, CANDELARIA N, BADER JO, BRICKEY GD AND ADAMS CE. 2009. The Effects of Manual Resistance Training on Fitness in Adolescents. J Strength Cond Res 23(8): 2287-2287.

EISENMANN JC, WICKEL EE, WELK GJ AND BLAIR SN. 2005. Relationship between adolescent fitness and fatness and cardiovascular disease risk factors in adulthood: The Aerobics Center Longitudinal Study (ACLS). Am Heart J 149(1): 46-53.

FAIGENBAUM AD, WESTCOTT WL, MICHELI LJ, OUTERBRIDGE AR, LONG CJ, LAROSA-LOUD R AND ZAICHKOWSKY LD. 1996. The effects of strength training and detraining on children. J Strength Cond Res 10(2): 109-114.

GARCÍA-PALLARÉS J AND IZQUIERDO M. 2011. Strategies to optimize concurrent training of strength and aerobic fitness for rowing and canoeing. Sports Med 41: 329-343.

GOLDEN SD AND EARP JA. 2012. Social ecological approaches to individuals and their contexts: twenty years of health education \& behavior health promotion interventions. Health Educ Behav 39(3): 364-372.

GREENING L, HARRELL K, LOW A AND FIELDER CE. 2011. Efficacy of a school-based childhood obesity intervention program in a rural southern community: Team Mississippi Project. Obesity 19(6): 1213-1219.

HASS CJ, FEIGENBAUM MS AND FRANKLIN BA. 2001. Prescription of resistance training for healthy populations. Sports Med 31: 953-964.

HENDRICKSON NR ET AL. 2010. Combined resistance and endurance training improves physical capacity and performance on tactical occupational tasks. Eur J Appl Physiol 109(6): 1197-1108.

IZQUIERDO-GABARREN M, GONZÁLEZ DE TXABARRI EXPÓSITO R, GARCÍA-PALLARÉS J, SÁNCHEZMEDINA L, DE VILLARREAL E AND IZQUIERDO M. 2010. Concurrent endurance and strength training not to failure optimizes performance gains. Med Sci Sports Exerc 42(6): 119- 128.

KAY SJ AND FIATARONE SINGH MA. 2006 The influence of physical activity on abdominal fat: a systematic review of the literature. Obes Rev 7(2): 183-200.

KVAAVIK E, KLEPP KI, TELL GS, MEYER HE AND BATTY GD. 2009. Physical fitness and physical activity at age 13 years as predictors of cardiovascular disease risk factors at ages 15, 25, 33, and 40 years: Extended followup of the Oslo Youth Study. Pediatrics 123(1): e80-e86.

MARFELL-JONES M, OLDS A AND CARTER SL. 2006. International Standards for Anthropometric Assessment. ISAK: Potchefstroom, South Africa.

MARTA CC. 2012. Determinant of physical fitness in prepubescent children and its training effects. $\mathrm{PhD}$ Thesis, University of Beira Interior, Covilhã, Portugal.

MARTA CC, MARINHO DA, BARBOSA TM, IZQUIERDO M AND MARQUES MC. 2012. Physical fitness differences between prepubescent boys and girls. J Strength Cond Res 26(7): 1756-1766.

NHANES. 2007. Let's improve our health. National Health and Nutrition Examination Survey III (NHANES III). Hyattsville, MD: US Department of Health and Human Services.

ORTEGA FB ET AL. 2008. Reliability of health- related physical fitness tests in European adolescents. The HELENA Study. Int J Obes 32(5): S49-57.

PATTERSON P, WIKSTEN DL, RAY L, FLANDERS C AND SANPHY D. 1996. The validity and reliability of the back saver sit-and-reach test in middle school girls and boys. Res Q Exerc Sport 67(4): 448-451. 
SMITH JJ, EATHER N, MORGAN PJ, PLOTNIKOFF RC, FAIGENBAUM AD AND LUBANS DR. 2014. The Health Benefits of Muscular Fitness for Children and Adolescents: A Systematic Review and Meta-Analysis. Sports Med 44(9): 1209-1223.

STRATTON G, FAIRCLOUGH SJ AND RIDGERS ND. 2008. Youth physical activity and sedentary behavior: Challenges and solutions. Champaign, IL: Human Kinetics Publishers. Leeds, England.

TAANILA H, HEMMINKI A, SUNI J, PIHLAJAMÄKI H AND PARKKARI J. 2011. Low physical fitness is a strong predictor of health problems among young men: a followup study of 1411 male conscripts. BMC Public Health 11: 590.
TOKMAKIDIS S, KASAMBALIS A AND CHRISTODOULOS A. 2006. Fitness levels of Greek primary schoolchildren in relationship to overweight and obesity. Eur J Pediatri 165(12): 867-874.

VANHELST J, MIKULOVIC J, FARDY P, BUI-XUAN G AND MARCHAND F. 2011. Effects of a multidisciplinary rehabilitation program on pediatric obesity: the CEMHaVi program. Int J Rehabil Res 34(2): 110-110.

WELK G AND MEREDITH MD. 2008. Fitnessgram ${ }^{\circledR}$ Activitygram Reference Guide. Dallas, TX: The Cooper Institute.

WONG T AND HARBER V. 2006. Lower excess postexercise oxygen consumption and altered Growth hormone and cortisol responses to exercise in obese men. J Clin Endocrin Metab 91: 2678- 2688. 